\title{
Período de Interferência de Plantas Daninhas em Mandioca (Manihot esculenta) NO NOROESTE DO PARANÁ ${ }^{1}$
}

\author{
Period of Weed Interference in Cassava (Manihot esculenta) in Northwestern Parana
}

\author{
BIFFE, D.F..$^{2,}{ }^{7}$, CONSTANTIN, J.. ${ }^{3,8}$, OLIVEIRA JR., R.S. ${ }^{3,8}$, FRANCHINI, L.H.M. ${ }^{4,8}$, RIOS, F.A. ${ }^{4,8}$, \\ BLAINSKI, E. ${ }^{4,8}$, ARANTES, J.G.Z. ${ }^{5,8}$, ALONSO, D.G. ${ }^{5,8}$ e CAVALIERI, S.D. ${ }^{6}$
}

\begin{abstract}
RESUMO - A mandioca é uma exploração agrícola importante no Estado do Paraná. No entanto, há limitadas informações relacionadas à interferência das plantas daninhas nessa cultura. Objetivou-se com este trabalho estimar o periodo crítico de prevenção à interferência (PCPI) na cultura da mandioca (variedade Fécula Branca), nas condições edafoclimáticas do noroeste do Paraná. O experimento foi dividido em dois grupos de tratamentos: com períodos crescentes na presença de plantas daninhas (PAI); e com periodos crescentes na ausência de plantas daninhas (PTPI). Foram identificadas as espécies de plantas daninhas e densidades de infestação na área e calculada a importância relativa (IR), avaliando-se também o estande da cultura e a produtividade de raizes comerciais. As principais plantas daninhas presentes na área e que apresentaram os maiores valores de IR foram Cenchrus echinatus e Brachiaria decumbens. Aceitando-se uma tolerância de redução de produtividade de 5\%, o PAI ajustado foi de 18 dias após o plantio da cultura, e o PTPI, de 100 dias. Concluiu-se que o PCPI da cultura para as condições edafoclimáticas do noroeste do Paraná situa-se entre 18 e 100 dias após o plantio.
\end{abstract}

Palavras-chave: Boltzmann, Gompertz, mato-interferência.

\begin{abstract}
Although cassava is a major agribusiness crop in Paraná, technical information related to weed interference in this crop is limited. This work aimed to evaluate the critical period of weed interference (PCPI) in cassava (var. Fécula Branca), for local climate and soil under northwestern Paraná conditions. The experiment was constituted of two groups: the first with increasing periods of weed interference (PAI) and the second with increasing periods without weed interference (PTPI). Main weed species in the area were identified and accounted for densities and relative importance (RI) during the cycle; crop stand and commercial root yield were also evaluated. The highest RI values were found for Cenchrus echinatus and Brachiaria decumbens. Considering a tolerance of 5\% of crop yield reduction, the adjusted PAI was 18 days after crop planting and PTPI was 100 days. Thus, it was concluded that the critical period of weed interference, under the northwestern Parana conditions, was from 18 to 100 days after planting.
\end{abstract}

Keywords: Boltzmann, Gompertz, weed interference.

\section{INTRODUÇÃO}

A mandioca é cultivada atualmente em mais de 180 países (FAO, 2008). No Brasil, a produção é estimada em 26 milhões de toneladas de raízes, com produtividade média de
14 toneladas por hectare (IBGE, 2008). O Estado do Paraná destaca-se como o terceiro maior produtor, responsável por aproximadamente $15 \%$ da produção, com produtividade média de 22 toneladas por hectare, bem acima da média nacional.

1 Recebido para publicação em 29.8.2009 e na forma revisada em 3.9.2010.

Parte da dissertação de mestrado apresentada pelo primeiro autor para obtenção do grau de Mestre em Agronomia, área de concentração em Proteção de Plantas.

2 Engo-o-Agr ${ }^{0}$, Doutorando, Universidade Estadual de Maringá - UEM, <biffeagro@hotmail.com>; ${ }^{3}$ Professor Associado, Núcleo de Estudos Avançados em Ciência das Plantas Daninhas - NAPD/UEM, Dep. de Agronomia, UEM, Av. Colombo, 5790, 87020-9000

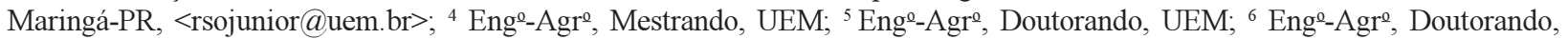
Universidade Estadual Paulista - UNESP, Botucatu; ${ }^{7}$ Bolsista Capes; ${ }^{8}$ Bolsista CNPq. 
Em todo o Paraná estão envolvidos diretamente com o setor mandioqueiro cerca de 30 mil produtores; a região noroeste do Estado detém $53,5 \%$ da área cultivada desta cultura. Do total de raízes tuberosas produzidas, aproximadamente $60 \%$ são destinadas à indústria de fécula e $40 \%$ à farinha de mandioca, abastecendo cerca de 40 fecularias e 80 farinheiras (SEAB, 2008).

Apesar da importância da região noroeste do Paraná no cenário mandioqueiro nacional, não há estudos que quantifiquem a magnitude das perdas provocadas por plantas daninhas nessa região.

O grau de interferência entre as plantas cultivadas e as plantas daninhas depende de diversos fatores relacionados à comunidade infestante (composição específica, densidade e distribuição) e à própria cultura (gênero, espécie ou cultivar, espaçamento entre sulcos e densidade de semeadura). Além disso, depende também da época e duração do periodo de convivência mútua, sendo modificado pelas condições edáficas e climáticas e pelos tratos culturais (Pitelli, 1985).

Os estudos sobre interferência das plantas daninhas em culturas agrícolas objetivam determinar os períodos críticos de interação entre culturas e comunidades infestantes. Esses periodos foram definidos por Pitelli \& Durigan (1984) como período anterior à interferência (PAI), período total de prevenção à interferência (PTPI) e período crítico de prevenção à interferência (PCPI), os quais, segundo Pitelli (1985), refletem a adequação das condições de implantação e manejo das culturas.

O conhecimento do PCPI determina a época conveniente para execução das práticas de controle, sejam elas mecânicas ou químicas. Com esse objetivo, diversos autores procuraram avaliar o período de competição entre a mandioca e as plantas daninhas em diversas regiões brasileiras.

Para Carvalho et al. (2004), o período de controle de plantas infestantes na cultura da mandioca, cultivar Cigana Preta (BGM 116), na cidade de Cruz das Almas, Bahia, foi entre 20 e 135 dias após a emergência da cultura.

Johanns \& Contiero (2006), em trabalho realizado em Marechal Cândido Rondon-PR, verificaram um PAI de 60 dias e PTPI de 90 dias para o cultivar Fécula Branca, indicando um PCPI de 60 a 90 dias após a plantio (DAP). Albuquerque et al. (2008), em ViçosaMG, determinaram que o período crítico para o cultivar Cacauzinha foi entre 25 e 75 DAP.

As variações entre os resultados demonstrados devem-se, em grande parte, às diferenças ambientais em que foram conduzidos os ensaios, aos cultivares, aos espaçamentos entre as plantas de mandioca e às composições específicas das comunidades infestantes. É relevante, portanto, desenvolver um conjunto de informações locais que subsidiem a tecnificação e as tomadas de decisão na condução da cultura da mandioca no noroeste do Paraná. Dessa forma, o objetivo deste trabalho foi determinar os períodos de interferência das plantas daninhas na cultura da mandioca (cultivar Fécula Branca), nas condições edafoclimáticas do noroeste do Paraná.

\section{MATERIAL E MÉTODOS}

O experimento foi realizado na Fazenda Experimental de Iguatemi (FEI), no município de Maringá-PR, pertencente à Universidade Estadual de Maringá, localizada a 2320'59" de latitude sul, $52^{\circ} 04^{\prime} 26^{\prime \prime}$ de longitude oeste de Greenwich e a $524 \mathrm{~m}$ de altitude. Segundo a classificação de Köppen, o clima para a localidade é do tipo Cfa, mesotérmico úmido, com chuvas de verão e de outono e verão quente; a precipitação observada durante a condução do experimento encontra-se na Tabela 1.

O solo da área experimental foi identificado como Argissolo Vermelho distrófico (Embrapa, 1999) de textura arenosa. As análises químicas e granulométricas encontram-se na Tabela 2 .

O preparo do solo adotado foi o convencional, realizando-se a descompactação do solo com um subsolador de haste modelo Ikeda, a uma profundidade aproximada de $0,40 \mathrm{~m}$. Posteriormente, realizaram-se duas gradagens, primeiramente com grade aradora a $0,20 \mathrm{~m}$ de profundidade e depois com o uso da grade niveladora, com a finalidade de destorroamento e homogeneização do terreno.

O plantio da cultura ocorreu em 13 de outubro de 2005. O cultivar de mandioca Fécula 
Tabela 1 - Precipitação mensal durante o experimento - 2005/2006, Maringá-PR

\begin{tabular}{|c|c|c|c|c|c|c|c|c|c|}
\hline \multicolumn{10}{|c|}{ Precipitação (mm) } \\
\hline out./05 & nov./05 & dez./05 & jan./05 & fev./05 & mar./05 & abr./05 & maio/05 & jun./05 & jul./05 \\
\hline 247,9 & 139,5 & 84,8 & 145,7 & 283,2 & 240,7 & 87,5 & 11,7 & 27,6 & 53,1 \\
\hline
\end{tabular}

Fonte: Estação Climatológica da Universidade Estadual de Maringá.

Tabela 2 - Resultado das análises químicas e granulométricas do solo utilizado no experimento de campo. Maringá-PR, 2006

\begin{tabular}{|c|c|c|c|c|c|c|c|c|c|c|}
\hline \multicolumn{2}{|c|}{$\mathrm{pH}$} & $\mathrm{Al}^{3+}$ & $\mathrm{H}^{+}+\mathrm{Al}^{3+}$ & $\mathrm{Ca}^{2+}$ & $\mathrm{Mg}^{2+}$ & $\mathrm{K}^{+}$ & SB & CTC & \multirow{2}{*}{$\begin{array}{c}\mathrm{P} \\
\left(\mathrm{mg} \mathrm{dm}^{-3}\right)\end{array}$} & \multirow{2}{*}{$\begin{array}{c}\mathrm{C} \\
\left(\mathrm{g} \mathrm{dm}^{-3}\right)\end{array}$} \\
\hline$\left(\mathrm{CaCl}_{2}\right)$ & $\left(\mathrm{H}_{2} \mathrm{O}\right)$ & \multicolumn{7}{|c|}{$\left(\mathrm{cmol}_{\mathrm{c}} \mathrm{dm}^{-3}\right)$} & & \\
\hline 5,3 & 6,1 & 0 & 3,71 & 3,82 & 1,69 & 0,19 & 5,7 & 8,41 & 7,58 & 6,11 \\
\hline \multicolumn{2}{|c|}{ Areia grossa } & \multicolumn{3}{|c|}{ Areia Fina } & \multicolumn{3}{|c|}{ Silte } & \multicolumn{3}{|c|}{ Argila } \\
\hline \multicolumn{11}{|c|}{$\left(\mathrm{g} \mathrm{kg}^{-1}\right)$} \\
\hline \multicolumn{2}{|c|}{450} & \multicolumn{3}{|c|}{390} & \multicolumn{3}{|c|}{50} & \multicolumn{3}{|c|}{110} \\
\hline
\end{tabular}

Fonte: Laboratório de Solos da Universidade Estadual de Maringá.

Branca foi cultivado pelo período de 280 dias, em espaçamento de 0,90 m entre linhas e $0,63 \mathrm{~m}$ entre plantas em cada linha. As manivas tinham aproximadamente $15 \mathrm{~cm}$ de comprimento, possuindo, em média, seis a oito gemas. A área útil de cada parcela foi constituída por quatro linhas, totalizando a largura $3,6 \mathrm{~m}$ e o comprimento, $5,0 \mathrm{~m}\left(18,0 \mathrm{~m}^{2}\right)$.

Os experimentos foram constituídos por dois grupos de tratamentos, com quatro repetições. No primeiro grupo, destinado à determinação do período anterior à interferência (PAI), foram avaliados 12 períodos crescentes de convivio da cultura com as plantas daninhas a partir do plantio (DAP): 0, 20, 40, 60, 80, 100, 120, 140, 160, 200, 240 e 280 dias. Após cada período de convivência, foi realizado o controle das plantas daninhas até a colheita. No segundo grupo, foram avaliados 12 períodos crescentes de controle das infestantes a partir do plantio: 0, 20, 40, 60, 80, 100, 120, 140, 160, 200, 240 e 280 dias. Após o término de cada periodo, permitiu-se que as plantas daninhas emergissem livremente, a fim de estimar o período total de prevenção à interferência (PTPI).

Para o levantamento fitossociológico da comunidade infestante, foram realizadas quatro amostragens por parcela, utilizando um quadrado de 0,50 x 0,50 m, lançado ao acaso dentro da área útil de cada parcela no fim de cada período de convivência da cultura com a comunidade infestante e aos 280 dias após o plantio (DAP) para os períodos crescentes de ausência de plantas daninhas.

Para cada espécie de planta daninha, foram determinadas a densidade, massa seca e frequência, a fim de obter o índice de valor de importância (IVI), calculado conforme a fórmula proposta por Mueller-Dombois \& Ellenberg (1974).

$$
I V I=D R+F R+D o R
$$

em que IVI representa o indice de valor de importância; $D R$ é a densidade relativa de cada espécie (razão entre o número de plantas de uma espécie e o total de plantas amostradas, expressa em porcentagem); $F R$ representa a frequência relativa (frequência com que a espécie ocorreu nas amostragens, expressa em porcentagem); e $D o R$ é a dominância relativa (razão entre a massa seca da espécie e o total de massa seca amostrado, expressa em porcentagem).

Procedeu-se ao cálculo da importância relativa $(I R)$ utilizando também a fórmula proposta por Mueller-Dombois \& Ellenberg (1974). A IR é determinada por meio da razão 
entre o IVI de cada espécie e o somatório dos IVIs de todas as espécies, expressa em porcentagem $(I R=I V I / I V I s)$.

O estande da cultura foi determinado pela contagem do número de plantas por parcela no momento da colheita (280 DAP), quando também foi realizada a pesagem das raízes após o arranque manual das plantas.

Todos os dados foram submetidos ao teste de normalidade de Shapiro-Wilk e à análise de variância. Os dados de estande foram então ajustados ao modelo de regressão não linear sigmoidal de Boltzmann, adaptado por Kuva et al. (2000), descrito por:

$$
Y=A_{2}+\left\{\left(A_{1}-A_{2}\right) /\left[1+\exp \left(\left(X-X_{0}\right) / d x\right)\right]\right\}
$$

em que $Y$ é o estande ( $\mathrm{n}^{\circ}$ plantas ha $\left.{ }^{-1}\right) ; A_{1}$ o estande $\left(\mathrm{n}^{\circ}\right.$ plantas $\left.\mathrm{ha}^{-1}\right)$ obtido nas parcelas mantidas na ausência de plantas daninhas durante todo o ciclo; $A_{2}$, o estande ( $\mathrm{n}^{\circ}$ plantas ha $\mathrm{a}^{-1}$ ) obtido nas parcelas mantidas na presença de plantas daninhas durante todo o ciclo; $X$, dias após o plantio (DAP); $X_{0}$, o limite superior do período de convivência ou controle que corresponde ao valor intermediário entre o estande máximo e o mínimo; e $D x$ é tg $\alpha$ no ponto $X_{0}$ (ponto de inflexão da curva).

Os dados de produtividade foram expressos em porcentagem e submetidos à análise de regressão não linear. Para os períodos em que a cultura conviveu com as plantas daninhas, o modelo ajustado foi novamente o não linear sigmoidal de Boltzmann, adaptado por Kuva et al. (2000), descrito por:

$$
Y=A_{2}+\left\{\left(A_{1}-A_{2}\right) /\left[1+\exp \left(\left(X-X_{0}\right) / d x\right)\right]\right\}
$$

em que, $Y$ é o rendimento da cultura, expresso em porcentagem; $A_{1}$ o rendimento máximo (\%) obtido no tratamento livre de plantas daninhas durante todo o ciclo da cultura; $A_{2}$ o rendimento mínimo obtido nas parcelas mantidas com plantas daninhas durante todo o ciclo; $X$, dias após o plantio (DAP); $X_{0}$, o limite superior do periodo de convivência ou controle que corresponde ao valor intermediário entre o rendimento máximo e o mínimo; e $D x$ é tg $\alpha$ no ponto $X_{0}$ (ponto de inflexão da curva).

Quanto aos períodos crescentes em que a cultura permaneceu no limpo, o modelo ajustado foi o de Gompertz, descrito por Knezevic et al. (2002):

$$
Y=A^{*} \operatorname{EXP}\{-\mathrm{EXP}[-(D A P-K) / B]\}
$$

em que $Y$ é o rendimento expresso em porcentagem; $A$ é igual à assíntota máxima em \%; $D A P$, dias após o plantio em que a cultura permaneceu livre de plantas daninhas; e $B$ e $K$ são constantes do modelo.

Com base nas equações de regressão, foram determinados os periodos de interferência das plantas daninhas, adotando-se um nível de tolerância de $5 \%$ de redução da produtividade da mandioca, em relação ao tratamento mantido na ausência dessas plantas, pois este nivel (5\%) de perda é o suficiente para que seja economicamente viável a realização do controle de plantas daninhas nessa cultura. Para todas as análises estatísticas foi utilizado o programa estatístico SAS 8.0 (SAS, 1999).

\section{RESULTADOS E DISCUSSÃO}

As principais espécies de plantas daninhas identificadas na área foram: Cenchrus echinatus, Brachiaria decumbens, Digitaria horizontalis, Sida rhombifolia, Acanthospermum hispidum, Ipomoea grandifolia, Raphanus sativus e Bidens pilosa.

Apesar da presença de Digitaria horizontalis, Sida rhombifolia e Acanthospermum hispidum em todos os períodos de convivio, destacaramse as espécies Cenchrus echinatus e Brachiaria decumbens como aquelas que apresentaram valores de IR superiores a $10 \%$ em todos os períodos (Figuras 1 e 2).

Cenchrus echinatus apresentou os maiores valores de IR nos períodos crescentes de convivência da cultura com as plantas daninhas (Figura 1) - fato esse atribuído ao banco de sementes da área e à plasticidade dessa espécie. Essa planta daninha pode emergir em todos os meses do ano, e o seu ciclo de vida pode variar de 60 a 210 dias, em função da temperatura e precipitação (Pacheco \& Marinis, 1984). A Brachiaria decumbens, por ser uma planta daninha perene, apresentou ganho de massa progressivo durante os períodos estudados, levando a valores de IR crescentes ao longo do tempo. 


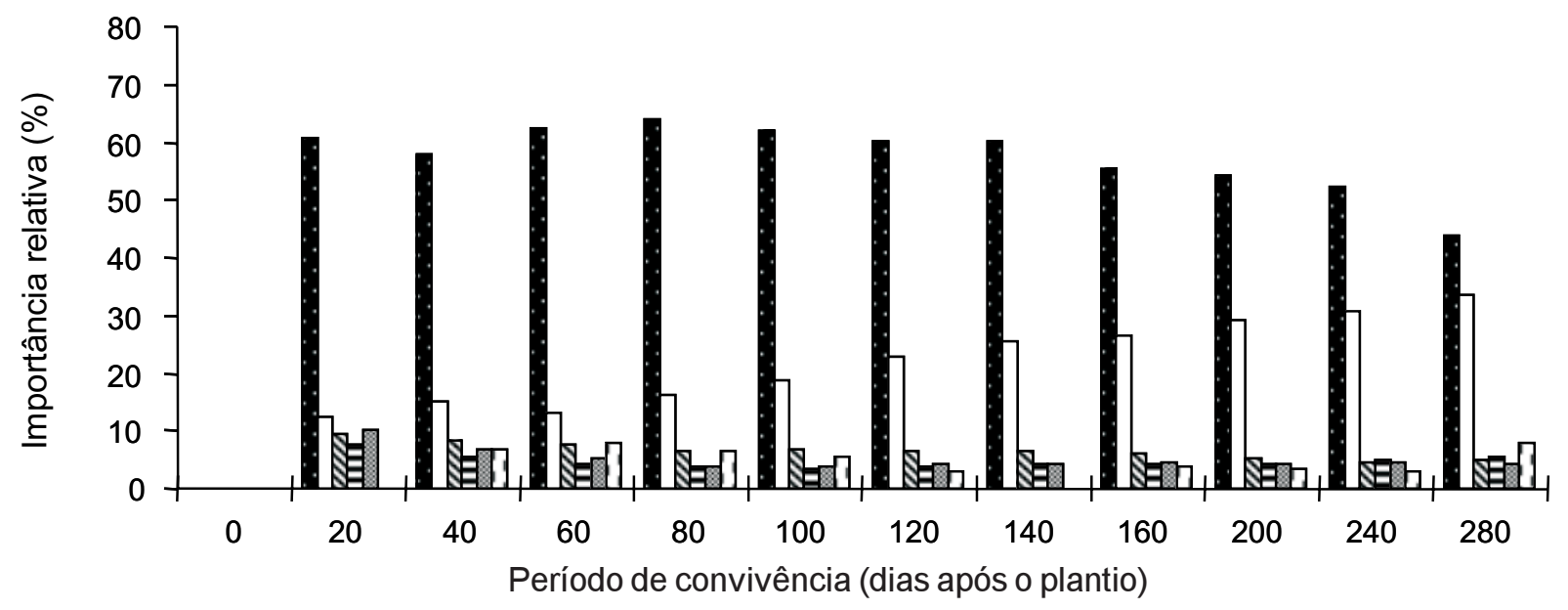

\section{- Cenchrus echinatus 目 Sida rhombifolia}

Brachiaria decumbens

Acanthospermum hispidum
$\mathbb{Q}$ Digitaria horizontalis

回 Outras

Figura 1 - Importância relativa de cada espécie de planta daninha no grupo de tratamentos em que a mandioca foi submetida a períodos crescentes de convivência com as plantas daninhas.

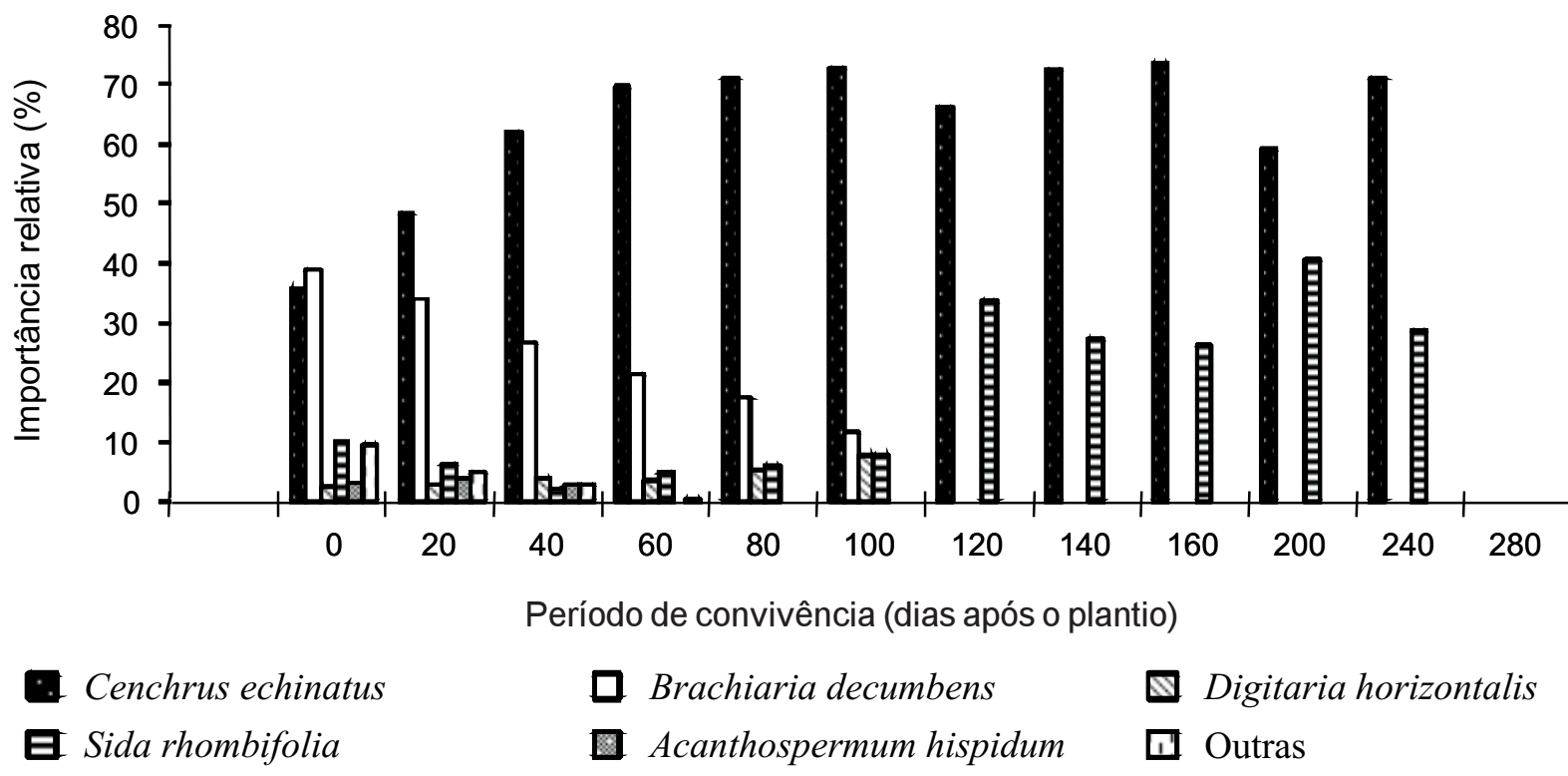

Figura 2 - Importância relativa de cada espécie de planta daninha no grupo de tratamentos em que a mandioca foi submetida a períodos crescentes de controle das plantas daninhas.

Nos períodos crescentes de controle (Figura 2), as espécies de maior importância foram Cenchrus echinatus, Brachiaria decumbens e Sida rhombifolia, sendo a primeira espécie aquela que em todos os períodos apresentou os maiores valores de IR, demonstrando que, mesmo em culturas já estabelecidas, sua habilidade de emergir é bastante elevada.
Brachiaria decumbens apresentou decréscimo de IR com o aumento do período de controle, até sua completa ausência aos 120 DAP, quando as plantas de mandioca praticamente cobriam todo o solo, evitando assim que a planta daninha emergisse. Correia et al. (2004) observaram que a germinação dessa espécie é comprometida quando há cobertura do solo. 
Sida rhombifolia demonstrou comportamento diferente do observado para Brachiaria decumbens, verificando-se germinação mesmo com a cobertura do solo promovida pela cultura. De acordo com Fleck et al. (2001), S. rhombifolia possui a característica de ser fotoblástica indiferente, ou seja, é capaz de germinar mesmo na ausência de luz.

Com relação ao estande da cultura (plantas ha ${ }^{-1}$ ), a regressão ajustada para os períodos crescentes de convívio foi: PAI $=1023+\{(15742-1023) /[1+\exp ($ DAP-99) $/ 33)]\}$, $r^{2}=0,89$; sua representação encontra-se na Figura 3.

Por meio da equação ajustada, observa-se que o estande máximo foi de 15.742 plantas ha(parâmetro $A_{1}$ ), no tratamento que permaneceu livre de plantas daninhas durante todo o ciclo da cultura.

Com o aumento do período em que a cultura conviveu com as plantas daninhas, o estande foi decrescendo - de maneira mais acentuada a partir dos 40 dias -, chegando ao estande minimo de 1.023 plantas ha ${ }^{-1}$ (parâmetro $\mathrm{A}_{2}$ ), no tratamento em que a cultura conviveu 280 dias com a comunidade infestante.

Aos 99 dias de convivio com as plantas daninhas, obteve-se o momento do ciclo em que houve a metade da redução do estande (parâmetro $\mathrm{X}_{0}$ ).

Para os períodos crescentes de controle de plantas daninhas, a equação ajustada foi: plantas ha ${ }^{-1}=14263+\{(3997+14263) /[1+\exp$ ((DAP-10)/15)]\} e $\mathrm{r}^{2}=0,89$, sendo representada na Figura 3.

Por meio da equação ajustada, observa-se que o estande máximo obtido para os períodos crescentes em que a cultura permaneceu livre de plantas daninhas foi de 14.263 plantas ha ${ }^{-1}$ (parâmetro $\mathrm{A}_{1}$ ), alcançado quando a cultura permaneceu no mínimo por 100 dias livre de interferência. Períodos maiores de controle não resultaram em aumento no número de plantas.

O estande mínimo foi de 3.997 plantas ha ${ }^{-1}$ (parâmetro $\mathrm{A}_{2}$ ), observado no tratamento em que não houve nenhum controle das plantas daninhas durante todo o ciclo. Já o ponto onde o controle das plantas daninhas propicia 50\% entre o máximo e o mínimo foi de 15 DAP (parâmetro $\mathrm{X}_{0}$ ).

A equação ajustada para o rendimento dos períodos crescentes em que a cultura conviveu com as plantas daninhas foi:

Produção relativa $(\%)=(-0,19)+\{(105,41+$ $0,19) / 1+\exp [(\mathrm{DAP}-59,91) / 18,56]\}$, com r $^{2}=0,99$ (Figura 4).

A produtividade máxima foi alcançada no tratamento que ficou sem plantas daninhas durante todo o ciclo da cultua. Com o incremento dos períodos de convivência, observase uma leve queda até próximo aos 20 DAP, a partir de onde a curva começa a declinar de maneira mais acentuada até chegar à perda

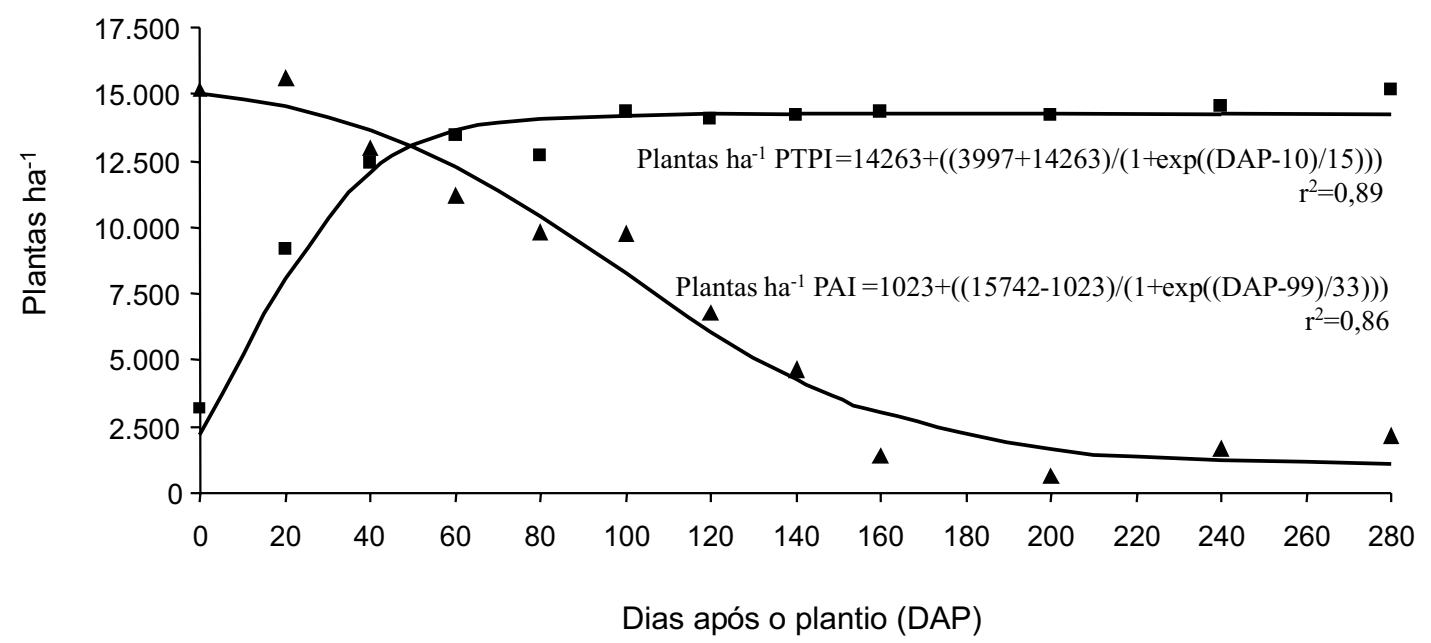

Figura 3 - Estande de mandioca em função de períodos crescentes de convívio ou ausência de plantas daninhas após o plantio. 
total de produção, aos 140 DAP. De acordo com o parâmetro ajustado da equação $\mathrm{X}_{0}, 60$ dias de convivência com as plantas daninhas foi o período suficiente para a redução de 50\% da produção relativa.

Partindo do pressuposto de que pequenas perdas de rendimento por interferência de plantas daninhas na cultura da mandioca não compensariam economicamente o uso de algum método de controle, aceitou-se uma tolerância de quebra de produção de 5\% - nível em que é economicamente viável a realização do controle das plantas daninhas. Dessa forma, pela equação ajustada, aos 18 DAP a produção relativa foi da ordem de $95 \%$, sendo esse ponto então considerado como PAI.

Ao estabelecer um PAI de 18 DAP, observase que nessa data a cultura encontrava-se em fase de emergência. No entanto, mesmo nessa fase precoce de desenvolvimento da cultura, foi estabelecido um processo de interferência das plantas daninhas sobre a mandioca. Uma vez que os principais efeitos de interferência, nesse caso, estão associados à competição por recursos do meio, é improvável que essas limitações possam ser significativas em um estádio tão precoce de desenvolvimento, e outros fatores podem estar envolvidos.

Segundo Ballaré \& Casal (2000), na cultura em que há presença de plantas daninhas, estas podem alterar, além da quantidade, a qualidade da luz incidente no solo e, assim, afetar o desenvolvimento da cultura. A variação na qualidade da luz é percebida por pigmentos como o fitocromo, criptocromo e fitotropina (Lamego et al., 2005).

A relação da radiação vermelho extremo/ vermelho, percebida pelos pigmentos, tem papel importante na indução de muitas alterações morfológicas na arquitetura das plantas, como crescimento do caule, dominância apical e ramificação (Ballare \& Casal, 2000). A detecção de elevada quantidade de radiação vermelho extremo faz com que as plantas aloquem maior disponibilidade de recursos para o crescimento da parte aérea e menor quantidade para o seu sistema radical, o que pode comprometer a disputa por recursos do solo (Rajcan \& Swanton, 2001).

O PAI encontrado (18 DAP) diverge do resultado obtido por Johanns \& Contiero (2006), que determinaram um PAI muito mais tardio (60 DAP), e situa-se próximo aos obtidos por Carvalho et al. (2004) (20 DAP) e Albuquerque et al. (2008) (25 DAP). Esse fato pode ser atribuido, como mencionado anteriormente, a diferenças edafoclimáticas, infestação e composição das plantas daninhas presentes na área, cultivar, espaçamento e outros diversos fatores específicos de cada local.

Para o PTPI, a equação ajustada foi: Produção relativa $=100,07 * \operatorname{EXP}\{-\mathrm{EXP}[-($ dias $39,45) / 20,58]\}$, com $r^{2}=0,92$. Novamente, aceitando uma redução de $5 \%$ na produção, o PTPI encontrado foi de 100 DAP.

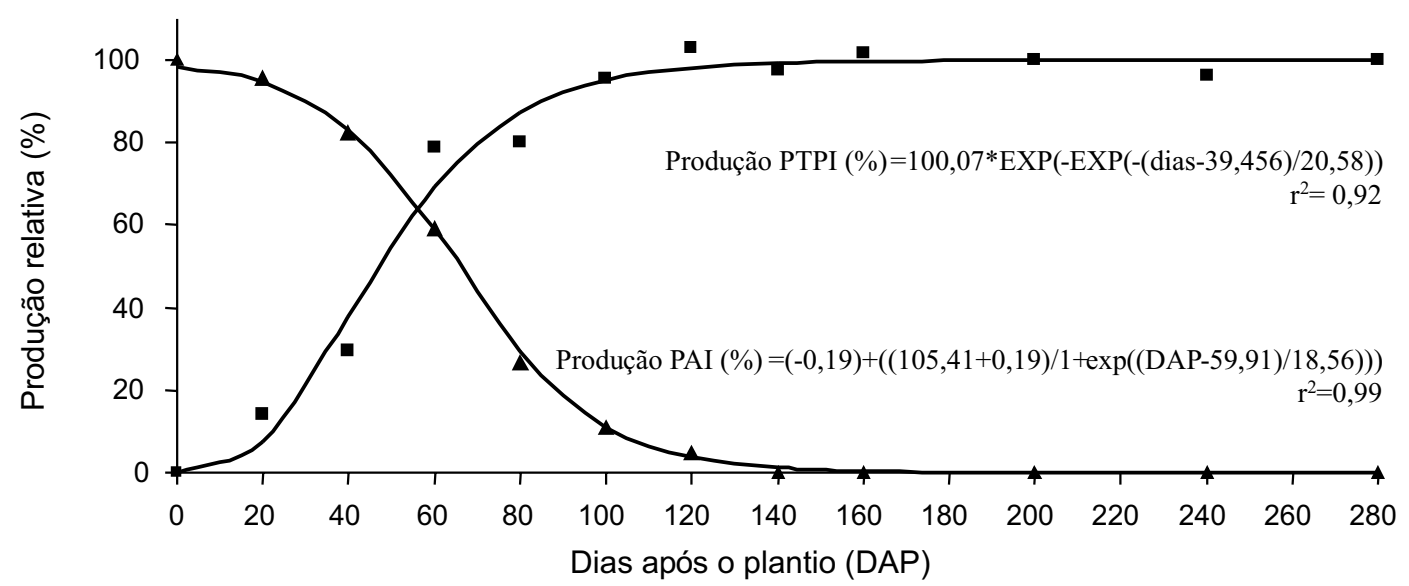

A Período de convivência com as plantas daninhas (PAI) - Período na ausência de plantas daninhas (PTPI)

Figura 4 - Produtividade relativa de raízes de mandioca (\%) submetida a diferentes períodos de ausência e convívio com plantas daninhas. 
A cultura da mandioca apresenta lento crescimento inicial (Lorenzi \& Dias, 1993), associado a um espaçamento de plantio relativamente grande, o que proporciona baixa capacidade competitiva com a comunidade infestante, sobretudo no que diz respeito ao sombreamento do solo, permitindo assim que fluxos de plantas daninhas possam emergir por um grande período de tempo. Esses fatos contribuem para um PTPI de 100 dias.

O resultado estabelecido para o PTPI (100 DAP) encontra-se próximo da média dos valores encontrados na literatura; os extremos foram determinados por Carvalho et al. (2004) e Albuquerque et al. (2008): 135 e 75 DAP, respectivamente.

Por fim, o período crítico de prevenção à interferência determinado neste trabalho na região noroeste do Paraná encontra-se entre 18 e 100 DAP. Estratégias de controle de plantas daninhas devem ser planejadas para esse periodo, visando preservar o máximo de potencial econômico de produção de raízes.

\section{LITERATURA CITADA}

ALBUQUERQUE, J. A. A. et al. Interferência de plantas daninhas sobre a produtividade da mandioca (Manihot esculenta). Planta Daninha, v. 26, n. 2, p. 279-289, 2008.

BALLARÉ, C. L.; CASAL, J. J. Light signals perceived by crop and weed plants. Field Crops Res., v. 67, n. 2 , p. 149-160, 2000.

CARVALHO, J. E. B. et al. Período de controle de plantas infestantes na cultura da mandioca no Estado da Bahia. Cruz das Almas: Embrapa, 2004. 7 p. (Comunicado Técnico, 109)

CORREIA, N. M.; DURIGAN, J. C. Emergência de plantas daninhas em solo coberto com palha de cana-de-açúcar. Planta Daninha, v. 22, n. 1, p. 11-17, 2004.

EMPRESA BRASILEIRA DE PESQUISA AGROPECUÁRIA - EMBRAPA. Centro Nacional de Pesquisa de Solos. Sistema brasileiro de classificação de solos. Brasília: Embrapa Produção de Informação; Rio de Janeiro: Embrapa Solos, 1999. 412 p

FOOD AND AGRICULTURE ORGANIZATION - FAO. Food and Agriculture Organization of The United Nations. Roma: 2008. Statitical Databases - FAO STAT.

Disponível em: <http://faostat.fao.org $>$. Acesso em: 15 maio 2008.

Planta Daninha, Viçosa-MG, v. 28, n. 3, p. 471-478, 2010
FLECK, N. G. et al. Efeitos de fontes nitrogenadas e de luz na germinação de sementes de Bidens pilosa e Sida rhombifolia. Ci. Agrotec., v. 25 n. 3 p. 592-600, 2001

\section{INSTITUTO BRASILEIRO DE GEOGRAFIA E} ESTATÍSTICA - IBGE. Previsão de safras. Disponível em $<\mathrm{http}: / /$ www.ibge.gov.br/home/estatistica/economia/ agropecuaria $>$. Acesso em:15 maio 2008.

JOHANNS, O; CONTIERO, R. L. Efeitos de diferentes períodos de controle e convivência de plantas daninhas com a cultura da mandioca. R. Ci. Agron., v. 37, n. 3, p. 326-331, 2006.

KNEZEVIC, S. Z. et al. Critical period for weed control: the concept and data analysis. Weed Sci., v. 50, n. 6, p. 773-786, 2002.

KUVA, M. A. et al. Períodos de interferência das plantas daninhas na cultura da cana-de-açúcar. I - Tiririca. Planta Daninha, v. 18 , n. 2, p. 241-251, 2000

LAMEGO, F. P. et al. Tolerância à interferência de plantas competidoras e habilidade de supressão por cultivares de soja - I. Resposta de variáveis de crescimento. Planta Daninha, v. 23 , n. 3, p. $405-414,2005$

LORENZI, J. O.; DIAS, C. A. C. Cultura da mandioca. Campinas: SAA/CATI, 1993. 41 p. (Boletim técnico, 211).

MUELLER-DOMBOIS, D.; ELLENBERG, H. Aims and methods of vegetation ecology. New York: John Wiley \& Sons, 1974. 547 p

PACHECO, R. P. B.; MARINIS, G. Ciclo de vida, estruturas reprodutivas e dispersão de populações experimentais de capim-carrapicho (Cenchrus echinatus L.). Planta Daninha, v. 7, n. 1, p. 58-64, 1984

PITELLI, R. A. Interferência das plantas daninhas em culturas agrícolas. Inf. Agropec., v. 11, n. 129, p. 16-27, 1985

PITELLI, R. A.; DURIGAN, J. C. Terminologia para períodos de controle e de convivência das plantas daninhas em culturas anuais e bianuais. In: CONGRESSO BRASILEIRO DE HERBICIDAS E PLANTAS DANINHAS, 15., 1984, Belo Horizonte. Resumos... Piracicaba: SBHED, 1984. p. 37

RAJCAN, I.; SWANTON, C. L. Understanding maize-weed competition: resource competition, light quality and the whole plant. Field Crops Res., v. 71, n. 2, p. 139-150, 2001.

SAS Institute. Statistical Analysis System Institute. Procedure guide for personal computers. Version 5. Cary: 1999.

SECRETARIA DA AGRICULTURA E ABASTECIMENTO DO PARANÁ - SEAB. Produção agrícola. Disponível em: $<$ http://www.seab.pr.gov.br/>. Acesso em: 15 maio 2008. 